\title{
A study on digital transformation in the healthcare sector of Bangladesh: Current scenario and the future roadmap
}

\section{Md. Mahfuzur Rahman Khan ${ }^{*}$, M. Mehedi Hasnat Al Amin ${ }^{2}$}

Institute of Social Welfare and Research, University of Dhaka, Dhaka, Bangladesh ${ }^{1 *}$

Department of Pharmaceutical Sciences, North South University, Dhaka, Bangladesh ${ }^{2}$

mahfuzur.rkm@gmail.com

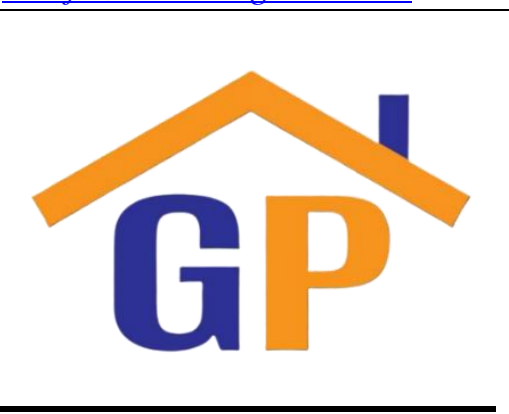

Article History

Received on 25 June 2021

Revised on 3 August 2021

Accepted on 13 August 2021

\begin{abstract}
Purpose: This study investigates the essential characteristics of digitalization and transformation in the healthcare sector in Bangladesh. It also examines the correlation between digital technology and developing factors in the current healthcare system and recommendations to overcome the crises still dwelling within the healthcare framework.
\end{abstract}

Research methodology: To gain a more vital understanding of the underlying insights of Digital Transformations of the healthcare sector of Bangladesh, the authors decided to conduct explorative research in qualitative format.

Results: As a developing country with increased economic solvency, Bangladesh is enduring a metamorphosis in medicine \& healthcare. Despite inequity in digital-initiated "equality," developing healthcare systems worldwide are getting in touch with digital technology.

Limitations: There are shortcomings in theoretical research as the previous practice of pedagogues and learners is challenged by new-age communication and the healthcare system based on digital technology.

Contribution: This study looks at the impressions of current Digital Transformation in pre-existing structures by the people of Bangladesh, and the study proposes a new national health servercentric approach for future solicitation.

Keywords: Digital transformation of healthcare, Healthcare sector of Bangladesh, Future roadmap of healthcare

How to cite: Khan, M. M. R., \& Al Amin, M. M. H. (2021). A study on digital transformation in the healthcare sector of Bangladesh: Current scenario and the future roadmap. Journal of Governance and Accountability Studies, 1(2), 163-176.

\section{Introduction}

The world is, indeed, ever-changing. Starting with the invention of fire, we have taken our innovations and achievements of science to a new height, but not all the nations are going at the same pace; some have reached a pinnacle of success, whereas others have fallen behind. Today, digital tools, particularly through connected objects or devices, measure, analyze, store, and sometimes share our health data: e-health. It has become almost impossible to escape it, regardless of our age and state of health. It, therefore, becomes essential because health is a subject that requires special precautions to learn to use wisely and ethically new information and communication technologies applied to this sensitive subject that is our health. Many things that people only used to read in science fiction are now taking place all around us and in many areas. Digitalization in the health sector is somewhat similar. The past few years have been seeing an unprecedented change in practically every one of the areas all over Bangladesh. The change from paper-based works to technology-based ones is evident in 
almost all sectors. Because of rapid globalization and the remarkable progression in data and correspondence innovation (ICT), the healthcare services area has been changed significantly preposterous decade in numerous world nations. The dissemination pace of computerized innovations in this area has immediately advanced in recent years (Ivatury et al., 2016). The progressive change of healthcare care could be the cornerstone of a fruitful change of healthcare care frameworks for improved productivity and viability to assist individuals. As of late, information and correspondence innovations have changed all areas of society. The potential for digital and social media healthcare is distinct from other sectors in several important ways (Bellon, 2016). The healthcare area is no exemption for this trend. Digital change of healthcare services makes an energizing, new domain of opportunities for clinical benefits in provincial zones that are all the while encountering development and recharging (Alami et al., 2017). Healthcare services are a fundamental piece of the economy of Bangladesh, and improving the healthcare care area is one of the supportable advancement objectives. Likewise, Health execution and monetary execution are interlinked. However, issues like unnecessary expenses, lacking assets, lopsided quality levels, and imbalances regarding admittance to healthcare care plague the current healthcare services industry. Exploration on the selection of e-Health, the piece of digitalization in agricultural nations, has shown that e-Health/mHealth can be likely answers for giving better admittance to healthcare services offices for patients, doctors attendants, and other healthcare care staffs, increment care quality, and improve cooperation. The change in generations has taken place, leaving room for practitioners who are just as attached to the profession as their predecessors but more sensitive to economic constraints and technological openings. The patients themselves become less passive, more educated, always connected, and if they are not aging, their children are for them; despite uses that are still often ephemeral and a technological maturity that is sometimes uncertain, connected objects are spreading.

The expansion of the digital healthcare system is the supreme wonder that makes the computerized change of healthcare services in developing countries like Bangladesh conceivable. In countries like Bangladesh, where resources are exceptionally restricted, individuals and leaders are reluctant to take difficulties and acknowledge recent technological progress; digitalizing healthcare care frameworks is considerably more troublesome. Even though Bangladesh has made an enormous improvement in numerous spaces in digitalization, however less in the healthcare services framework, in Bangladesh, the correct arrangements, associations, assets, and foundations, ICTs can be tremendous assets in possession of those attempting to improve healthcare services. Digital web platforms, different apps, pay-per-click advertising, pay-per-click campaigns are modern strategies for a company's investment and upgrading area for the digitalization of the healthcare sector (Khan and Basak, 2021). Shockingly, this area has been portrayed with some uniqueness: patients have fewer self-administration choices than in different areas and less admittance to confided in data on the nature of care on offer. Since the onset of the epidemic, Bangladesh has taken digital action as quickly as possible. Systematic increase in corona testing capacity, isolation of COVID-19 infected people, identification of people who encounter them, taking extraordinary measures for people seriously ill with the disease, and involving all people in the epidemic with accurate coronavirus information m-health and e-services are tremendously made. Bangladesh has shown considerable activity. The Healthcare sector has become the blessing of ICT in Bangladesh which has been recognized as one of 57 countries in the world with a critical shortage in health workforces (hospitals, doctors, nurses, and midwives number below 2.28 per 1000 population) and several beds (4 per 10,000) in hospitals (Mostafa, 2016). The literature reviews on these themes are exceptionally restricted, and the information on the digitalization of the healthcare sector in Bangladesh was significantly gathered from secondary sources. However, some primary data was collected by interviewing a few respondents about their views on digitalization and transformation in the healthcare sector of Bangladesh. Most previous studies have only focused on eHealth applications in Bangladesh like m-Health, telemedicine, electronic health record, telecare (Hoque et al., 2014). This paper mostly centers on digitalization, which is gradually occurring in the healthcare sector and its cycles, factors, and barriers in adaptation in Bangladesh. As a prospect of vision 2021 of computerized Bangladesh, ICT in healthcare care, particularly advanced administrations, is dangerously progressing. 


\section{Literature \& hypothesis development}

Digitalization is the capacity to change the entire world into an advanced one. With the appearance of smartphones and web networks across the world, the entire world is associated with a digital summit. However, in any event, when the entire world and any remaining related areas change in an advanced way still the healthcare area is stale in changing. Digitalization incorporates critical zones, such as reconFigureuring the client incentive and reshaping the working model-how it is conveyed. For the most part, it is perceived to be utilizing computers, the internet, mobile telephone, and different advances to improve the patients' healthcare status. It includes utilizing data advances to improve healthcare as a rule and the healthcare care framework specifically. Significant advances in programming languages and operating systems in recent years likewise have set the establishments of digital health care (Bauer, 2002). Digital health is understood to mean the convergence of digital technologies - e-mail, cellular and text messages - and health and medical care. Its purpose is simple: to make health care delivery more efficient, to link health systems, to increase the individualization and precision of treatment and health promotion, and to help health professionals and patients manage the challenges - diseases and health risks, as well as promoting health and well-being. Innovation and digitalization assume a critical part in making a dynamic and organized system in the healthcare service sector (Kalarthi, 2016). Digitalization is a tedious interaction in the healthcare area. Since this is various partners ought to be counseled, and it ought to be tried on different occasions to see if it addresses the issues of individuals adequately before being executed in reality (Tamilarasi and Cheriyan, 2019). Throughout the advancements, it is assessed that the pace of digitalization will increase the number of healthcare opportunities. Diversification in digitalization leads to the development of health care services (Khan and Basak, 2021). The World Health Organization, which is continually researching the design and spread of healthcare services, has acknowledged the expected force of computerized advancements expanding the availability, quality, and productivity of healthcare administrations (World Health Organization, 2016). It is energizing to see this degree of movement in developing nations since ICT is frequently more affordable and more pervasive in faroff pieces of the creating scene than numerous different types of innovation or healthcare administration foundations. Expanding all-inclusive admittance to healthcare administration that populaces may some way or another pass up should be one of the best-expected advantages of digitalization of healthcare, and created nations are similarly prone to gain from developing nations as the other way around. There are extremely few well-trained individuals, and there is a strong demand for capacity building and experience sharing, especially for implementation and policymaking (Ahmed et al., 2014). Research on the adoption of e-Health which is the part of digitalization in developing countries, has shown that e-Health/m-Health can be potential solutions to provide better access to healthcare facilities for patients, physicians, nurses, and other healthcare staff, increase care quality, and improve collaboration (Khalifehsoltani \& Gerami, 2010).

\section{Hypothesis development}

The advent of digital technology in our daily life is also changing the practice of healthcare. Far from replacing medicine, automation strengthens the links between patients and caregivers because the connected patient takes more charge by intensifying exchanges with caregivers between formal consultations. This "continuous" medicine reassures and involves the patients who become stakeholders in their health. Understanding their illness and the reasons for treatment can better follow their doctor's advice and consult them wisely as hypotheses are frequently specific predictions of what will occur in a given investigation. If the hypothesis the authors developed below is correct, there is a precise prediction regarding a new phenomenon that should be observed. It is a simple explanation based on a few essential concepts that the authors found significant development in the digitalized transformation of the healthcare sector of Bangladesh. These are created by considering existing evidence and applying logic to predict what will occur in the specific setting of interest.

$\mathrm{H}_{1}=$ There is a significant development in the digitalized transformation of the healthcare sector of Bangladesh

$\mathrm{H}_{0}=$ There is no significant development in the digitalized transformation of the healthcare sector of Bangladesh 
Digitalization in healthcare services is at an expanding stage in Bangladesh. Indeed, Bangladesh has not yet been set up to adapt to ICT selection in the healthcare sector appropriately. Bangladesh healthcare sector is providing e-service to the mass people through information technologies, i.e., usage of the mobile phone for healthcare service, telemedicine, telemedicine service in community clinics, pregnancy care advice through SMS, digital training facility and internet connectivity in the health system (Management Information System Directorate General of Health Services, 2017).

\section{Research methodology}

Qualitative research helps produce detailed findings where no previous or secondary data is available and helps produce findings beyond the immediate margins of the specific study (Mack, 2005). Therefore, to gain a more robust understanding of the underlying insights of Digital Transformations of the healthcare sector of Bangladesh, the authors decided to conduct the study as exploratory research in qualitative format.

\subsection{Objective of the study}

This study aims to work on the impressions of current Digital Transformation in pre-existing structures by the people of Bangladesh, and the study proposes a new national health server-centric approach for future solicitation. This study investigates the essential characteristics of digitalization and transformation in the healthcare segment. This study also aimed:

- To identify impressions of current digital transformation in pre-existing structure by the people of Bangladesh.

- To identify the challenges faced by authorities to Digital Transformation in the healthcare sector.

- To propose a new national health server-centric approach for future solicitation.

Common characteristics of the village according to Suhartono (2000:14), namely:

1. Generally located or very close to the center of the agricultural area (agrarian)

2. In the region, agriculture is the dominant economic activity

3. Soil mastery factor determines the pattern of people's lives

4. Unlike in large towns or towns where most of the population is migrants, the villager population is more "replaced by its own"

5. Social control is more informal, and interaction between villagers is more personal in the form of face-to-face

6. It has a relatively high level of homogeneity and relatively tighter social ties than the city

\subsection{Questions developed based on the Objectives}

Based on the above village understandings, the village has its own autonomy and territorial boundaries to regulate and take care of the villagers' interests. With the enacting of Law No. 6 of 2014 on Villages, the village is required to be independent in carrying out its government affairs, especially in the management of village finances. The source of village income derived from the village's original income is a form of village independence in managing finance. So the village is not dependent on the transfer of funds from the local government or the central government.

The understanding the perception and knowledge about the digitalization of the healthcare sector and the possibility of transformation towards a digital healthcare sector in Bangladesh can be understood in a more precise and conscience manner with the result of the survey, which was conducted on a random population with the help of Google forms. No general description of the participants was recorded, and their personal information as the survey was born in random people with the random questionnaires.

- Do people believe Healthcare management in Bangladesh can be developed like developed countries in the world?

- How would people rate the system and the current Healthcare system and hospital management system through which the healthcare system is provided? 
- How would people feel if all of the Patient histories are being stored in their NID cards? Their mediation and diagnosis procedure will be conducted using their NID card, Number, or Fingerprint ID; they can view all of their previous medication data (but not update/rewrite it) through a website. How would people feel about it?

- Do people believe that a digital approach in the healthcare system may alleviate current problems ( brokerage, Multiple medications, Fake doctors, and pharmacies) with healthcare management?

- Do people believe digitalization in Hospitals, Pharmacies, and diagnostic centers and enabling them to operate under a national health server can be an epoch-making approach in the Digitalization of Bangladesh?

- What are the significant sides of development that people feel need to be happening to make Bangladesh's healthcare system a well maintained and sound healthcare system for Bangladesh?

- Do people believe a Digital healthcare management system with national health servers, preservation of patient profile data in a health server, accessibility through NID card for the treatment and diagnosis can induce the developments people selected above?

- Do people think such a system's inculcation can help improve doctor-patient communication regarding patient history management, drug information about the patient, pharmacovigilance, and patient safety?

- Do people think such inculcation of the system may cause problems (tick the difficulties you feel may take place)

- Do people believe these problems can be alleviated in the long run, which can help develop a better healthcare system in Bangladesh?

\subsection{Data \& findings}

The study's findings were decisive, depicted below in pie charts and bar diagrams per questions and answers submitted. There were ten questionnaires with answers confirming affirmations and denying off the scenario that is taking place. The authors did few case studies and FGD (focus group discussion) to understand the scenarios better.

\section{Do you believe Healthcare management in Bangladesh can be developed like developed countries in the world? \\ 60 responses}
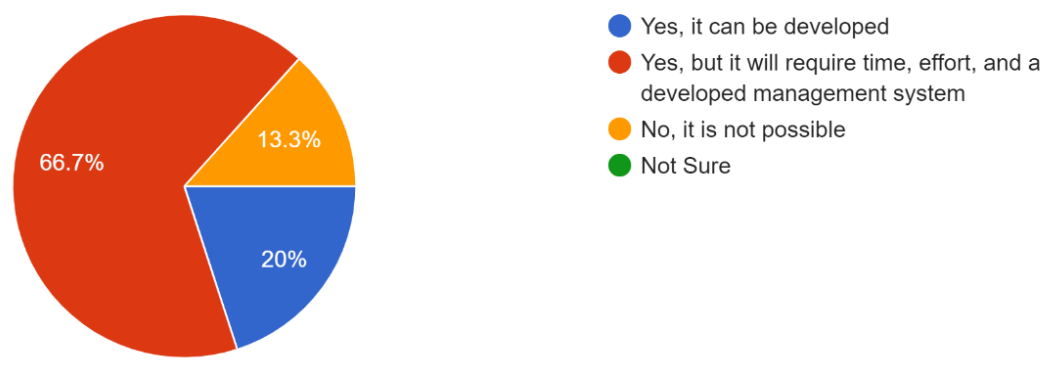

Figure 1. Pie chart of participants' answers to the first question of the questionnaire.

For the first question, $66.7 \%$ of people answered that Bangladesh's current health care management system could be developed like developed countries in the world. Still, it will require a definite amount of time, effort, and a well-developed management system to make the health care system of Bangladesh a Before the developed countries, $20 \%$ of people's perception is that the system healthcare management system in Bangladesh can be designed like developed countries. In contrast, $13.3 \%$ of people deny the fact. According to them, it is not possible. 
2. The current Healthcare system and hospital management system through which the healthcare system is provided, how would you rate the system?

60 responses
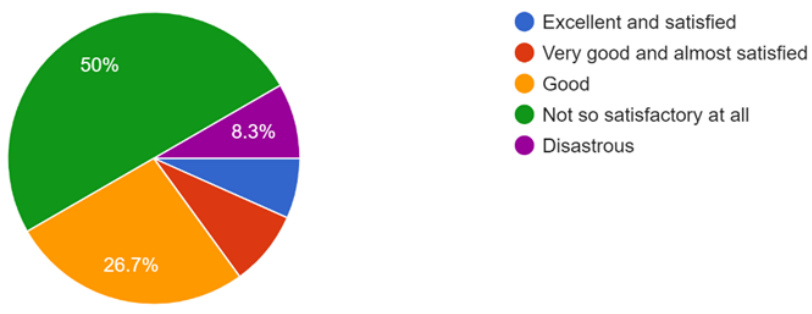

Figure 2. Pie chart of participants' answers to the second question of the questionnaire.

This question was provided to understand the attitude and perception regarding the current systems and procedures basedwithin Bangladesh's current healthcare management system. In this questionnaire, around 50\% of the people answered that Bangladesh's current health care system and hospital management system are not satisfactory. At all, $8.3 \%$ of people regard the system as a disastrous one. Around $26.7 \%$ of people things that the current health care system and hospital management system of Bangladesh is a good one. The majority of answers suggest that most people, around $1 / 3$ of the population to whom the questionnaires have been through, realize Bangladesh's health care management system is not satisfactory.

\section{How would you feel if all of your Patient histories are being stored in your NID card, your mediation and diagnosis procedure will be conduct... through a website, How would you feel about it? 60 responses}

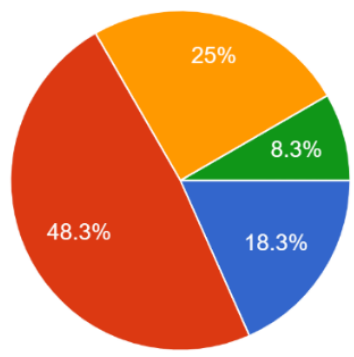

Very satisfactory and comforting

Good Idea, but I need to know more about it

May become problematic with various complications

It is not required at all

Figure 3. Pie chart of participants' answers to the third question of the questionnaire.

This question tried to find out about the attitude and understanding of the population regarding a digital healthcare system with the help of the NID card, the storing of patient history in a server system the management of diagnosis through a digital health care management system. In the answer, around $48.3 \%$ of people depicted that the idea would be a good one, but generally, people would require more knowledge. $25 \%$ of the population showed that it might become problematic with various complications lying ahead. $18.3 \%$ of people find this idea very comforting and helpful for Bangladesh's digital health care and management system. Few people, $8.3 \%$, realize that such a system is not required for a country like Bangladesh. 
4. Do you believe that a digital approach in the healthcare system may alleviate current problems ( brokerage, Multiple medications, Fake doctors and pharmacies, etc.) with healthcare management? 60 responses

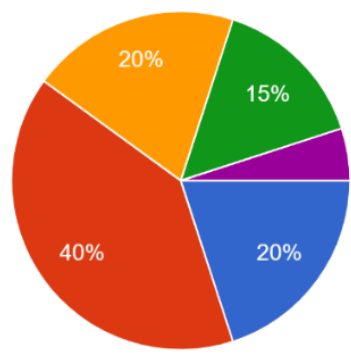

Definitely

It can be a better approach to alleviate the problem

Could be a solution

May not be a solution

Will not serve as a solution

Figure 4. Pie chart of participants' answers to the fourth question of the questionnaire.

This question tried to depict the perception of the general people regarding the formulation of such a system to remove or reduce the problems associated with the current health care and management system. Around $20 \%$ of the general population answer that it surely would be a perfect solution to alleviate and reduce the problem. A majority of $40 \%$ of people answered that it could be a better approach to lessen the pain. At $20 \%$ of the people realized it could solve the current problem, and $15 \%$ of people realized it might not be a solution at all. The minor number of people, less than $5 \%$, realized it would not serve as a solution for the current problems associated with the health care system of Bangladesh.

5. Do you believe digitalization in Hospitals, Pharmacies, and diagnostic centers and enabling them to operate under a national health server can be a...king approach in the Digitalization of Bangladesh? 60 responses

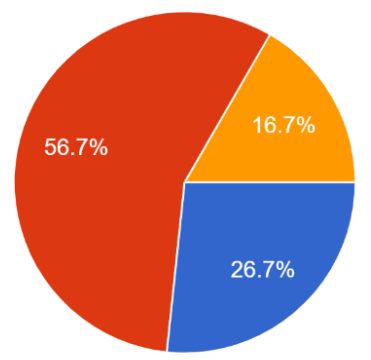

Definitely

Yes, but it will require many other steps to be added alongside with it

Not sure

Not at all

Figure 5. Pie chart of participants' answers to the fifth question of the questionnaire.

This questionnaire tried to find out the idea of general people of Bangladesh regarding the digitalization of hospitals pharmacy and diagnostic centers to be more accurate and effective in regarding patient management, to the overall digitalization of the health care system of Bangladesh when they will be operated under a national health server alongside with NID card identification system. 56.7\% think it is a better approach, but it will require many other steps to be added. The process itself is not only a stand-alone procedure that can develop the health care system of Bangladesh. Whereas $26.7 \%$ of people think this digitalization of the healthcare system of Bangladesh is an excellent measure to digitalize the health care system of Bangladesh and develop it. $16.7 \%$ of people are not sure whether this procedure may impact the development of the health care system of Bangladesh. 
8. Do you think such inculcation of this system can help to improve doctor-patient communication regarding patient history management, drug inform... patient, pharmacovigilance, and patient safety? 60 responses
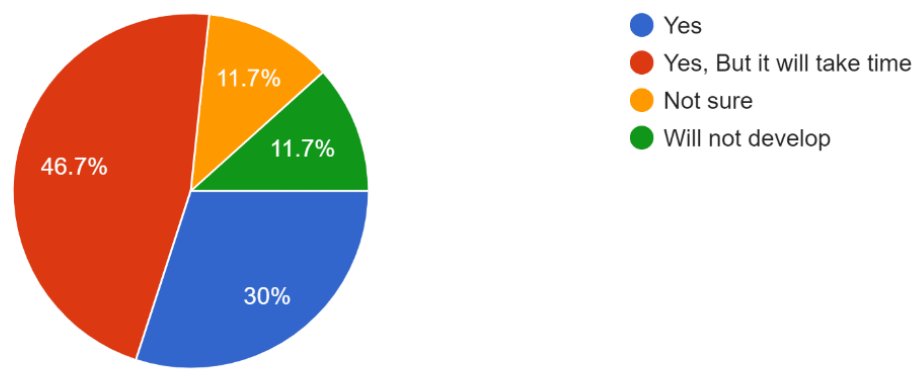

Figure 8. Pie chart of participants' answers to the eighth question of the questionnaire.

This question tried to focus on the farther sighted problems that affect the health care system of Bangladesh and will require more attention and management shortly (problems like pharmacovigilance, patient safety, drug information, and prevention of abuse, these problems are almost in neglect within the health care system of Bangladesh but nowadays the problems are Bing bought to the limelight). A majority of participants explained that this system could improve the current conditions associated with the problems $46.7 \%, 30 \%$ of the general population realized this system could develop these underlying problems. $11.7 \%$ of people were not sure and remain adamant that the system will not induce these underlying problems.

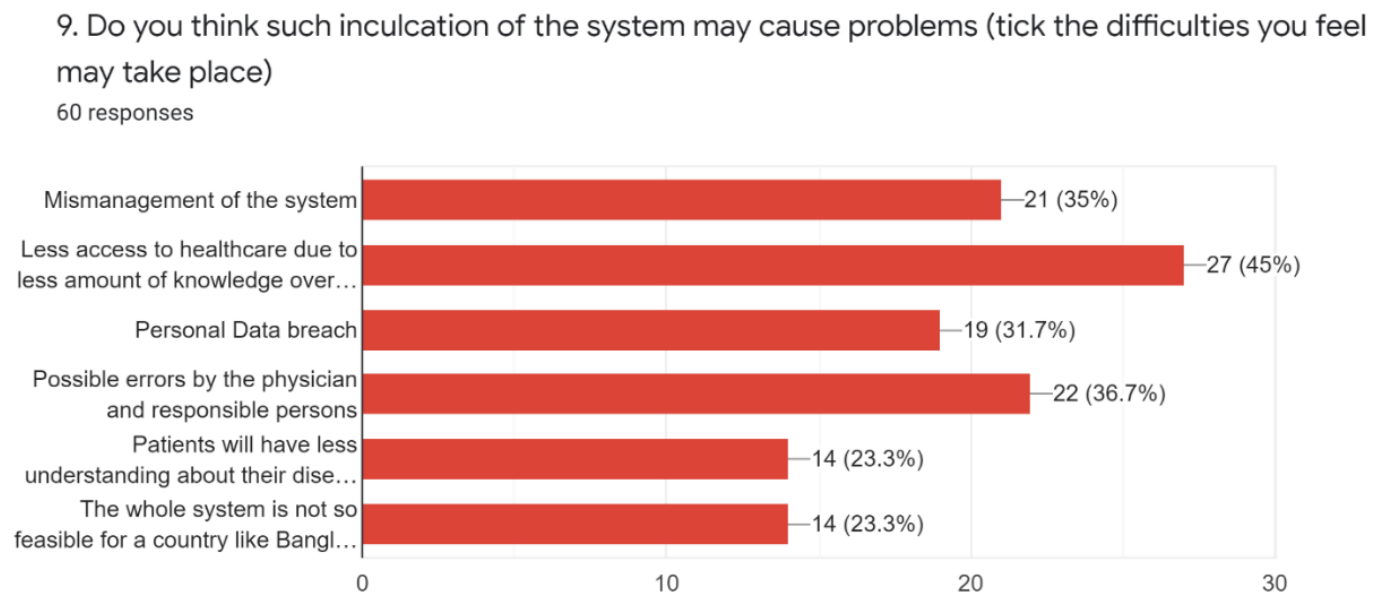

Figure 9. Bar diagram of participants' answers to the ninth question of the questionnaire.

This questionnaire tries to find out the problems that may associate with the system. in this aspect, most of the audience, $45 \%$, gave their thoughts on the issue. A significant number of people would have less access to healthcare due to less knowledge of the system. 36.7\% of people think dot physicians and responsible persons may cause possible errors while the health care provider. $35 \%$ of the people's idea was that the system's mismanagement should also be a fatal problem. The other issues like personal data breach $31.7 \%$, less understanding of their diseases, $23.3 \%$, and another $23.3 \%$ feel the system itself is not feasible for a country like Bangladesh. 
10. Do you believe these problems can be alleviated in the long run, and this system can help develop a better healthcare system in Bangladesh?

60 responses
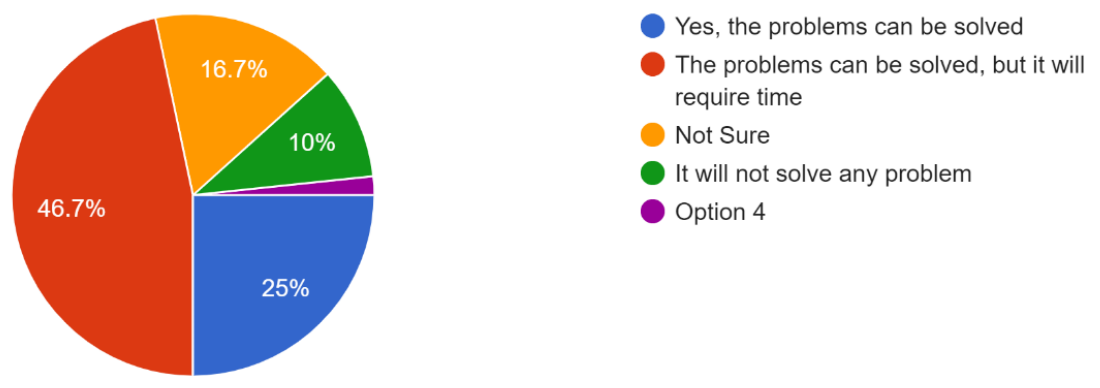

Figure 10. Pie chart of participants' answers to the tenth question of the questionnaire.

The questionnaire's last question is the majority of the people, $46.7 \%$, answer that the problem can be solved, but it will require time. Nevertheless, $25 \%$ of the people where is static that the problem can be solved. $16.7 \%$ of people were unsure about the outcome, but $10 \%$ realized that the underlying problem would not be solved by teaching such a system in Bangladesh. The understanding of positive attitude towards the development of the system of health care of Bangladesh was found out from the question regarding product off the system (question no 1), the digitalization of the hospital's pharmacies and diagnostic centers (question 5 ), using off central servers and an ID cards to induce developments in the system (question no 7), and alleviation of the problems associated with the health care management system of Bangladesh through the inculcation of such system. From the above discussion, the authors reject the null hypothesis and conclude dots there is a significant development in the digitalized transformation of the healthcare sector of Bangladesh.

\section{Results and discussion}

From questionnaires, the authors were set to find out three certain aspects for the performance of the result. Positive attitude towards the development of the system, second was understanding the current system, third was how the system could solve the problems associated with the current health care management system, and finally attitude towards the proposed approach. Aforementioned, the hospital facility and the medical practitioner's number possess a tremendous gap in healthcare. Current medical care frameworks presently depend on cutting-edge Figureuring techniques and advancements, like IoT gadgets and mists, to gather and break down close-to-home healthcare information at unprecedented scale and profundity. Patients, specialists, medical services suppliers, and analysts rely upon insightful models obtained from such information sources to distantly screen patients, early-analyze infections, and discover customized therapies and drugs. The above national health server-centric approach covers the hospital entrance, ticket counter, doctor counseling or doctors chamber, pharmacy counseling or retail pharmacy (model pharmacy or model pharmacy shop and patient data display application. Every hospital and individual should have the following items for the smooth performance of the proposed model. For individuals: Chip-enabled national ID card in which a specific code/data will be stored. Upon punching on any of the outlets, (doctors/physician chamber/retail pharmacy/ diagnostics chamber the data can be updated/rewritten. App installed in a smartphone that can scan a QR code installed in the card to review the patient data in the App. The App should be compatible with both Android/IOS platforms/ desktop. A specific website should be set up in which patients can log in with their NID number and a dedicated password. The password can be updated using the Mobile number registered with the NID card. An E-mail address can also be settled out with the NID card database for hastening the procedure.

\subsection{Case Study on current scenario}

Bangladesh faces multiple challenges because of the risk of contracting the virus itself and its impact on overstretched health services, to the knock-on repercussions from containment measures on work, 
health, education, and earnings (Khan, 2020a). The health sector is no different. Misunderstandings, debates, and even clashes between doctors and patients are often heard in Bangladesh. These led to Figurehts, hospital vandalism, and lawsuits. Patients complain that doctors do not listen to them, answer questions, and do not give them enough time. Hospitalized patients also do not receive adequate information about their treatment. On the other hand, physicians complain that patients often do not give accurate information about their disease. Ms. Shoma, a patient who complains while taking treatment from a prominent hospital in Dhaka city,

"Every morning when the big doctor came round, we were all told to get out of the ward. After he left, a junior would write medicines, tests in the file. After seeing that, the nurse would ask us to bring medicine. However, we were never told how much the patient was improving, why any medicine was being given. They would have been annoyed if I had asked the juniors." (Shoma Akter, 33)

Mr. Habib had taken his baby boy to Dhaka Medical College Hospital after his head was severed. After the stitches, the doctor of the surgery ward prescribed antibiotics and some medicines without listening to anything. Asked which drugs worked, the doctor shouted, went outside to the drug store, and asked. In government hospitals and private hospitals where many people pay for advanced treatment, patients complain that they are not adequately informed about their treatment, medicines, or operations. There are allegations that even the doctors in the chamber give medical prescriptions without listening to the patients. Nazma Akhter was admitted to a private hospital in Dhaka with a stomach problem. She stated:

"After the doctor came and saw the patient, his junior would come and tell us, 'You have to do this, you have to do that test.' Nevertheless, the original physician never spoke well. He used to do many tests every day. Nevertheless, I have never been able to explain why these tests are being done, whether they are needed at all." (Nazma Akhter, 29)

\subsection{Healthcare startups in Bangladesh}

In recent years, Bangladesh has been fortunate to have witnessed the rise of new businesses in the health sector. The digital healthcare movement is driving many startups in Bangladesh, many of which are dedicated to mobile healthcare and female healthcare.

Table 1. Popular healthcare startups in Bangladesh

\begin{tabular}{|c|c|l|}
\hline Name & Foundation Year & \multicolumn{1}{c|}{ Remarks } \\
\hline Maya & 2011 & $\begin{array}{l}\text { Maya is a digital platform that connects anyone with a } \\
\text { phone to experts, such as doctors and therapists, to get the } \\
\text { advice they need -hassle-free and stigma-free. }\end{array}$ \\
\hline Doctorola & 2015 & $\begin{array}{l}\text { Doctorola is an online platform that allows patients to find } \\
\text { doctors in their area and book appointments online. } \\
\text { Provides a consumer-facing website supported by a } \\
\text { sophisticated call center that checks for availability and } \\
\text { book appointments. }\end{array}$ \\
\hline CMED Health & 2016 & $\begin{array}{l}\text { CMED Health offers a variety of intelligent health } \\
\text { monitoring devices for vital sign assessment. The firm } \\
\text { sells gadgets that test and monitor blood pressure, glucose } \\
\text { levels, temperature, blood oxygen saturation, weight, and } \\
\text { height. The gadgets may communicate with a mobile } \\
\text { application to share data and enable remote monitoring. }\end{array}$ \\
\hline Moner Bondhu & 2016 & $\begin{array}{l}\text { Moner Bondhu provides access to trained, experienced } \\
\text { psychologists, therapists, clinical social workers, and } \\
\text { professional counseling services, allowing anyone } \\
\text { struggling with life's challenges to get help whenever and } \\
\text { wherever they need it. }\end{array}$ \\
\hline Olwel & $\begin{array}{l}\text { Olwel provides "critical doorstep healthcare service for } \\
\text { patients who prefer to receive medical consultation at their } \\
\text { home." }\end{array}$ \\
\hline
\end{tabular}




\begin{tabular}{|l|l|l|}
\hline \multirow{3}{*}{2018} & $\begin{array}{l}\text { Pulse is a platform for online teleconsultations and doctor } \\
\text { appointment booking. It enables users to search for } \\
\text { doctors and schedule appointments with them. It provides } \\
\text { a mobile app that allows users to store health data such as } \\
\text { medications, previous prescriptions, scanned past and } \\
\text { future medical reports, jpeg images, etc. }\end{array}$ \\
\hline
\end{tabular}

Other elements of these digitalized healthcare startups include arranging patients' appointments, accepting video calls, collecting online payments for live video consultations, instant messaging, clinical notes, e-prescriptions, encrypted file share options, and virtual chambers.

"Providing online medical access to individuals in rural Bangladesh would be a game-changer, as an online medical consultation is both handy and simple to use, especially for people who reside in rural regions and do not have access to doctors when they need one. Pulse has begun the process of enrolling doctors and launching digital services across the country." (Sonia Bashir Kabir, co-founder of Pulse)

These joint ventures may ensure the right to healthcare for all people. Local authorities in urban areas need to develop a multi-sectoral structure coordinated at all levels of administration and consider the fragile situation and problems that exist within that structure by identifying the people outside the security system and bringing them under protection. The mental response to the blackout instead of the actual blackout can be the trigger for the downturn. When this is the situation, essentially trusting that the cerebrum will recuperate is insufficient; the downturn likewise should be dealt with (Khan et al., 2021). Such technology is being used in third-tier healthcare to improve the overall healthcare facilities in the country. Such a procedure can offer many options to develop, integrate, manage, and Excel further in Bangladesh's digital healthcare system.

\section{Conclusion}

There is a need to turn around to tackle this epidemic so that the healthcare sector can be taken to a more modern and advanced level. Achieving this goal requires increasing allocations to the health sector, adequately recruiting skilled and trained health workers in the right places, increasing the chances of the general public getting better treatment, and strengthening the health information system. Apart from this, monitoring vaccination and health care equipment management and health testing centers need to be intensified. At the same time, it is essential to be prepared for such crises in the future. To deal with such a global crisis, we need to establish a comprehensive global strategy and continuous communication between all societies, which will make the general public aware and capable of protecting themselves. Outbreaks appear to be exacerbated during this time. For this reason, utmost importance should be given to restore the demand for health care and its fulfillment. Bangladesh needs to formulate a health policy in line with global trends. That health policy should emphasize prevention, early screening, and identification. In this case, the primary health care system and primary health workers should increase their respective roles. There is a growing recognition that the activities of community health workers at the local level are effective in providing preventive, promotional, and curative health care and that they can eliminate inequalities in access to health care.

For this reason, primary health care must be strengthened as one of the main tasks in achieving the goal of ensuring global health care. The Corona epidemic has brought public health to the forefront of policy discussions. As people all continue to Figureht to limit the devastating effects of this epidemic, we need to discuss policy in the long run with public health in mind. Because we now understand the devastating effects of not having a long-term public health policy. Anyone particular organization or organization cannot handle public health. Various sectors of society are involved with it. There are education, environment, infrastructure, and many more such sectors directly linked to public health. Customized healthcare may now be entering its long-awaited golden era because of the rise in available data, testing capabilities, and cutting-edge technology. More effective treatments can be utilized if a person's genetic makeup is better understood. A genetic test might be used in the future to detect what genetic variants a woman has before she is treated for breast cancer, for example. 
For this reason, all public health-related sectors need to work together with a common goal. The World Health Organization works closely with other countries, including Bangladesh, to achieve some bold and complex global health care goals. Besides, there are scopes of opportunities and improvements with the inculcation of such technology. However, such a system requires a positive attitude of ordinary people and well-trained staff and management to manage and maintain such technology and techniques. As part of the formation of Digital Bangladesh, a telemedicine system was introduced in medical services with the help of technology. In this way, people in remote areas can advise specialist doctors of big hospitals in Dhaka through video conferencing. Apart from this, specialist doctors also treat these patients through mobile phones and e-mails. Patients do not have to pay any additional fee to get health care through a telemedicine center.

Regarding implementing policy to ensure digital health intervention in Bangladesh, he said the present government provides more than 32 medicines through 14,000 community clinics in the country. Tabs have been provided for recording the services of healthcare providers and messages for vaccinations and medicines for mothers and children. A digital monitoring system has been set up to manage all health services so that health services can be ensured and an internet connection is provided to all hospitals and clinics. There are no particular guidelines and guidelines for applying ICT proficiently and viably in the healthcare services area. In Bangladesh, the job of ICT relies upon clear conditions, and a few uses of ICT are more utilized than others. Bangladesh is receiving a driven public ICT/eHealth strategy to consolidate ICTs into their healthcare framework, lining up with the Digital Bangladesh Vision 2021. Under the umbrella of digitalization, the computerized stations are joined into the healthcare specialist organizations, such as telehealth, telecare, m-Health, eHealth, Electronic Health Record (EHR), Video Conferencing, Telemedicine, etc. The advanced healthcare development is driving a massive range of new businesses around there, many working in versatile healthcare services for the last mile populace. Digital health refers to using electronic and computer tools, services, and methods to deliver health services or promote better health. By better controlling information flow, technology can give doctors the capacity to speed up and improve their diagnostic capabilities. Increasingly powerful computing capabilities will assist in filtering, sorting, and organizing the enormous volumes of information already being collected in electronic health records, allowing a patient's most serious health concern to be identified sooner. Because of their ubiquity and ease of use, mobile health (mHealth) applications and wearable technology can change healthcare delivery. Smartphones are already being used as a practical health tool, for example, in conjunction with specific attachments to provide laboratory-based tests for infectious illnesses at home or the point of treatment.

The adoption of digital healthcare in Bangladesh involves creating a network of systems that allow a person to securely connect and share their health information with a network of authorized health professionals. Increasingly, it provides the tools and information to help better understand and manage health. Bangladesh has developed a strategic strategy to strengthen this industry, which is an essential element of the country's economy. However, the healthcare sector's receptivity to digital change is mixed. In this regard, it may be stated that service providers must develop a high-quality ICT-based health service that is accessible and widely available throughout the country. Government policy guidelines for monitoring and overseeing the digitization of the healthcare industry should be developed. Separate studies on e-health, m-health, telecare, telehealth, electronic health records, telemedicine, digital startups, and video conferencing can be undertaken in the future. In any case, the entire digitalization in the health care area can happen just when straightforwardness exists. The consciousness of health by individuals is a significant benefit, assisting the organizations with building up the applications, or programming has explicitly intended to observe one's health and wellbeing. The openness of the medical services area from any place required is likewise the main thrust to digitalization. This paper has focused on digitalization in the healthcare sector as a whole, but future researchers can focus on e-Health, m-Health, Blockchain, IoT, etc. Future research can define and measure the level of influence of various intermediate variables, and future research can put forward hypotheses based on the model and conduct an empirical analysis to demonstrate its value in practical applications $\underline{(\text { Khan, 2020b) }}$. Digital health has the potential to be a significant facilitator of 
improved healthcare outcomes in these areas. This is especially true in developing nations' rural or remote areas, where people are half as likely as their urban counterparts to have access to care.

\section{Acknowledgment}

The authors acknowledge there was no external funding support; the authors solely contributed accordingly in every part of the paper.

\section{References}

Ahmed, T., Lucas, H., Khan, A. S., Islam, R., Bhuiya, A., \& Iqbal, M. (2014). eHealth and mHealth initiatives in Bangladesh: a scoping study. BMC health services research, 14(1), 1-9.

Alami, H., Gagnon, M. P., \& Fortin, J. P. (2017). Digital health and the challenge of health systems transformation. Mhealth, 3.

Bauer, J. C. (2002). Rural America and the digital transformation of health care: New perspectives on the future. Journal of Legal Medicine, 23(1), 73-83.

Bellon, E., Feron, M., Deprez, T., Reynders, R., \& Van den Bosch, B. (2011). Trends in PACS architecture. European journal of radiology, 78(2), 199-204.

Hoque, M. R., Mazmum, M. F. A., \& Bao, Y. (2014). e-Health in Bangladesh: current status, challenges, and future direction. The International Technology Management Review, 4(2), 8796.

Ivatury, G., Moore, J., \& Bloch, A. (2009). A doctor in your pocket: health hotlines in developing countries. Innovations: Technology, Governance, Globalization, 4(1), 119-153.

Kalarthi, Z. M. (2016). A review paper on smart health care system using internet of things. International Journal of Research in Engineering and Technology, 5(03), 8084.

Khalifehsoltani, S. N., \& Gerami, M. R. (2010, January). E-health challenges, opportunities and experiences of developing countries. In 2010 International Conference on e-Education, eBusiness, e-Management and e-Learning (pp. 264-268). IEEE.

Khan, M. M. R. (2020a). Covid-19's impact on Fresh Graduate's Job Market in Bangladesh: An observational study. Journal of Business and Management Studies, 2(1), 40-48.

Khan, M. M. R. (2020b). Strategic human resource management in facilitating the organizational performance: Birds-eye view from Bangladesh. Annals of Management and Organization Research, 2(1), 13-24. https://doi.org/10.35912/amor.v2i1.575

Khan, M. M. R., \& Basak, K. (2021). Shifts in Pharma-Marketing Trends in Post COVID-19 Era. International Journal of Multidisciplinary: Applied Business and Education Research, 2(2), 172-178.

Khan, M. M. R., Khan, M. W. R., \& Basak, K. (2021). Study on Influence of Macro-trauma Injuries on the Psychology of a Sportsman. Journal of Sports and Physical Education Studies, 1(1), 0509.

Mack, N. (2005). Qualitative research methods: A data collector's field guide.

Management Information System, Directorate General of Health Services (2017). Health Bulletin 2017. Ministry of Health and Family Welfare, Bangladesh. Retrieved from https://www.dghs.gov.bd/images/docs/Publicaations/HealthBulletin2017

Mostafa, R., Rahman, G. E., Hasan, G. M., Kabir, A., Rahman, A., \& Ashik, S. (2010, July). Proposed deployments to provide e-healthcare in Bangladesh: Urban and rural perspectives. In The 12th IEEE International Conference on e-Health Networking, Applications and Services (pp. 361-366). IEEE.

Tamilarasi, S., \& Cheriyan, A. A. S. H. I. E. K. (2019). Clinics to Clicks: The Digital Transformation of Health Sector in India. A Journal of Composition Theory, 12(9), 1131-1137.

World Health Organization. (2016). Global diffusion of eHealth: making universal health coverage achievable. Author. Retrieved from http://apps.who.int/iris/bitstream/handle/10665/252529. 